\title{
Sex differences in the impact of the Mediterranean diet on systemic inflammation
}

\author{
Alexandra Bédard ${ }^{1,2}$, Benoît Lamarche ${ }^{1,2}$, Louise Corneau', Sylvie Dodin ${ }^{1,3}$ and Simone Lemieux ${ }^{1,2^{*}}$
}

\begin{abstract}
Background: Some intervention trials have reported a reduction in systemic inflammation with the Mediterranean diet (MedDiet) while others have observed no effect. Despite the fact that sex differences have been highlighted in the inflammatory regulation, it is still not known whether MedDiet exerts similar effects on systemic inflammation in men and women. The aim of this study was therefore to investigate sex differences in the effects of the MedDiet on high-sensitivity C-reactive protein (hs-CRP).

Findings: Participants were 35 men and 27 premenopausal women (24-53 years) presenting a slightly deteriorated lipid profile. All foods were provided to participants during a 4-week isocaloric MedDiet. At baseline, women had higher hs-CRP concentrations than men $(P=0.03)$. No sex difference was observed in hs-CRP response to the MedDiet ( $P$ for sex-by-time interaction $=0.36$ ), with both men and women experiencing no change (respectively $P=0.62$ and $P>0.99$ ). When subgroups were formed according to hs-CRP concentration before the MedDiet phase, men with elevated baseline values ( $\geq 2 \mathrm{mg} / \mathrm{l}$ ) experienced a reduction in hs-CRP over time with the MedDiet $(-26.5 \%)$ while an increase was observed in men with lower baseline values (+96.6\%; P for group-by-time interaction $=0.02$ ). This pattern of change was not observed in women.

Conclusions: Results from this controlled feeding study suggest that men and women have similar effects from the MedDiet on systemic inflammation. The individual's overall inflammatory status seems to influence these effects, but only in men.
\end{abstract}

Trial registration: This clinical trial was registered at www.clinicaltrials.gov as NCT01293344.

Keywords: Sex, Mediterranean diet, C-reactive protein, Men, Women

\section{Findings} Introduction

The implication of low-grade, chronic inflammation in the formation, progression and rupture of atherosclerotic plaques is now well-recognized [1]. Accordingly, elevated C-reactive protein (CRP), a marker reflecting the individual's systemic inflammatory status, has been consistently associated with increased risk of coronary heart disease events [2,3] and type 2 diabetes [4]. There is growing evidence that adopting the traditional Mediterranean diet (MedDiet) reduces systemic inflammation [5]. The MedDiet is characterized by an abundance of

\footnotetext{
* Correspondence: Simone.Lemieux@fsaa.ulaval.ca

'Institute of Nutrition and Functional Foods (INAF), 2440 Hochelaga

Boulevard, Laval University, Québec, Qc G1V 0A6, Canada

${ }^{2}$ School of Nutrition, Pavillon Paul-Comtois, 2425 rue de l'Agriculture, Laval

University, Québec, Qc GIV OA6, Canada

Full list of author information is available at the end of the article
}

plant-based foods, such as fruits, vegetables, whole grain cereals, nuts and legumes; olive oil as the main source of fat; moderate amounts of fish, poultry, dairy products and eggs; relatively low amounts of red meat and sweets and moderate amounts of red wine with meals [6]. However, even if most of the intervention trials have reported that this food pattern reduces CRP concentrations [7-11], some have observed no effects [12-15]. Accordingly, the investigation of factors that may influence the antiinflammatory effects of this healthy food pattern is of great interest. Sex has been highlighted as a determinant of the inflammatory regulation. In fact women are characterized by a higher inflammatory overall burden than men [16]. Also, effects of sex hormones on inflammatory status have been documented, estrogens being now recognized for their anti-inflammatory properties in women [17]. However it is still not known whether MedDiet exerts the 
same effect on inflammation in men and women. The aim of this study was therefore to investigate sex differences in the effects of the MedDiet on high-sensitivity C-reactive protein (hs-CRP) concentrations. As estrogens have antiinflammatory properties in premenopausal women [17], and that the MedDiet has been previously shown to reduce estrogen concentrations in women [18], we hypothesized that premenopausal women benefit less from the anti-inflammatory effects of the MedDiet than men.

\section{Methods}

\section{Participants}

Thirty-eight men and 32 premenopausal women (2453 years) took part of this study. The main inclusion criteria were to have a slightly elevated low-density lipoprotein cholesterol (LDL-C) concentrations (between 3.4 and $4.9 \mathrm{mmol} / \mathrm{l}$ ) or total cholesterol to high-density lipoprotein cholesterol (HDL-C) ratio $\geq 5.0$, and at least one of the four following cardiovascular disease (CVD) risk factors: waist circumference $>94 \mathrm{~cm}$ in men and $>80 \mathrm{~cm}$ in women; triacylglycerol (TAG) concentration $\geq 1.7 \mathrm{mmol} / \mathrm{l}$; fasting glycemia between 6.1 and $6.9 \mathrm{mmol} / \mathrm{l}$ and/or blood pressure levels $\geq 130 / 85 \mathrm{~mm} \mathrm{Hg}$. More details about inclusion and exclusion criteria have been reported elsewhere [19]. Women using systemic hormonal contraceptives were excluded. All subjects signed an informed consent form before their inclusion in the study, which has been approved by the Laval University Research Ethics Committee. Power analysis indicated that a total sample size of $n=62$ is sufficient to detect significant changes in hs-CRP concentrations (repeated measures, within-between interaction) with a small effect-size estimate (Cohen's d of 0.20 ), and with an $\alpha=0.05$ and a power (1- $\beta$ error probability) of 0.95 (G*Power Version 3.0.10, Franz Faul, Universität Kiel, Germany).

\section{Study design}

The study protocol consisted in a 4-week run-in period, immediately followed by a 4-week fully-controlled MedDiet phase. Firstly, during the 4-week run-in period, participants had to comply with the recommendations of the Canada's Food Guide [20] as prescribed by a registered dietician. The purpose of this run-in period was to ensure similar dietary habits between men and women prior the controlled MedDiet phase, a goal that has been reached as previously reported [19]. Briefly, Canada's Food Guide is an educational tool which promotes healthy eating for Canadians in order to reduce the risk of many chronic diseases and to achieve overall health and vitality. It indicates the recommended number of food guide servings per day for each of the four food groups (vegetables and fruits, grain products, milk and alternatives, and meat and alternatives) according to the age and sex of individuals.
Thereafter, during a 4-week fully-controlled feeding phase, subjects consumed an experimental MedDiet formulated to be concordant with the characteristics of the traditional MedDiet [6]. Details about the composition of the MedDiet are given in Table 1 and Table 2, as previously reported in other publications $[19,21]$. Subjects were instructed to consume only the foods and beverages provided to them, which corresponded to $100 \%$ of their estimated energy needs. More precisely, energy needs were estimated by averaging the energy requirements estimated by a validated FFQ [22] administrated at the beginning of the run-in period and energy needs as determined by the Harris-Benedict formula. Body weight was measured on weekdays just before lunch and in case of body weight variation, energy intake was modified. The amount of each food/drink provided to each participant during the MedDiet was proportional to his/her estimated energy needs. In order to evaluate compliance, participants were asked to note on a checklist foods consumed and, if needed, the amount of foods not consumed for each day of the controlled MedDiet phase. The overall compliance calculated from the food checklist in men and women was respectively $97.9 \pm$ $3.6 \%$ and $97.6 \pm 3.2 \%$. Since sex hormones may influence the inflammatory status [17], women's feeding was shortened or prolonged if needed in order to be able to carry out all tests in the early follicular phase of their

Table 1 Servings of key foods of the Mediterranean pyramid consumed daily during the experimental Mediterranean diet phase for a $10460 \mathrm{~kJ} / \mathrm{d}(2500 \mathrm{kcal} / \mathrm{d})$ menu

\begin{tabular}{lc}
\hline Key foods $^{\mathrm{a}}$ & MedDiet (servings/d) \\
\hline Olive oil (ml) & 43.3 \\
Whole grains products & 5.7 \\
Fruits and Vegetables & 16.1 \\
Legumes & 0.5 \\
Nuts & 0.9 \\
Cheese and yogurt & 2.0 \\
Fish & 1.3 \\
Poultry & 0.9 \\
Eggs & 0.3 \\
Sweets & 0.3 \\
Red meat & 0.2 \\
Red wine & 1.3 \\
\hline
\end{tabular}

MedDiet Mediterranean diet

a Extra virgin and virgin olive oils were used. Serving size for whole grains products $=125 \mathrm{ml}$ (rice, pasta, bulgur, couscous), one bread piece or $30 \mathrm{~g}$ cereal; Serving size for fruits and vegetables $=125 \mathrm{ml}$; Serving size for legumes $=175 \mathrm{ml}$ and for nuts $=30 \mathrm{~g}$; Serving size for fish, poultry and red meat $=75 \mathrm{~g}$; Serving size for egg $=100 \mathrm{~g}$; Serving size for dairy products (mostly low fat cheese and yogurt) $=50 \mathrm{~g}$ cheese, $175 \mathrm{~g}$ yogurt and $250 \mathrm{ml}$ milk; Serving size for red wine $=150 \mathrm{ml}$

This table has been previously published in other publications $[19,21]$ 
Table 2 Daily nutritional composition of the experimental Mediterranean diet for a $10460 \mathrm{~kJ} / \mathrm{d}(2500 \mathrm{kcal} / \mathrm{d})$ menu

\begin{tabular}{lc}
\hline & MedDiet \\
& For $10460 \mathrm{~kJ} / \mathrm{d}(2500 \mathrm{kcal} / \mathrm{d})$ \\
\hline Energy ( $\mathrm{K})$ & 10460 \\
Carbohydrate (\% of total energy) & 46.0 \\
Fiber (g) & 42.3 \\
Protein (\% of total energy) & 17.0 \\
Fat (\% of total energy) & 32.0 \\
SFA (\% of total energy) & 6.7 \\
MUFA (\% of total energy) & 18.1 \\
PUFA (\% of total energy) & 4.7 \\
Cholesterol (mg) & 289.7 \\
Alcohol (\% of total energy) & 5.0 \\
MUFA to SFA ratio & 2.7 \\
Sodium (mg) & 3039 \\
\hline
\end{tabular}

MedDiet Mediterranean diet

This table has been previously published in other publications $[19,21]$

menstrual cycle (mean duration of the feeding period in women $28.8 \pm 4.3$ days).

\section{CRP measurements}

Fasting blood samples were collected after the run-in period (i.e. just before the controlled MedDiet phase, referred as baseline values) and immediately after the MedDiet. Serum concentrations of hs-CRP were measured using a high-sensitivity enzyme immunoassay test kit (BioCheck Inc., Foster City, CA; coefficients of variation: intra-assay $\leq 7.5 \%$, inter-assay $\leq 4.1 \%$ ).

\section{Statistical analysis}

Statistical analyses were performed with the SAS statistical package version 9.4 (SAS Institute Inc., Cary, NC, USA). Time and sex-by-time interaction effects on hs-CRP concentrations were assessed by using MIXED procedures for repeated measurements followed by Tukey-Kramer tests. Participants with hs-CRP concentrations greater than 10 $\mathrm{mg} / \mathrm{l}$ (indicative of an acute inflammation process [23]) before or after the MedDiet phase were excluded from our analyses (three men and five women). A P $\leq 0.05$ was considered as statistically significant.

\section{Results}

At baseline, men and women had similar mean age and body mass index (BMI) (Table 3). However, men were characterized by higher body weight and waist circumference, and displayed higher values for TAG, total cholesterol/HDL-C ratio, systolic and diastolic blood pressures and fasting glucose, and a lower value for HDL-cholesterol than women (Table 3). The degree of concordance of the diet with the traditional MedDiet, as assessed by the Mediterranean score after the run-in phase based on the Canada's Food Guide [24], was similar in men and women (Table 3).

At baseline, women had higher hs-CRP concentrations than men $(1.53 \pm 1.49 \mathrm{mg} / \mathrm{l}$ for men and $2.32 \pm 1.63 \mathrm{mg} / \mathrm{l}$ for women; P for sex difference $=0.03$ ). No change was observed for hs-CRP concentrations over time with the MedDiet in both men and women (respectively $\mathrm{P}=0.62$ and $\mathrm{P}>0.99$, $\mathrm{P}$ for sex-by-time interaction $=0.36$; Fig. 1 ).

When subgroups were formed according to hs-CRP concentrations before the MedDiet phase, men with

Table 3 Characteristics of men and women at baseline ${ }^{a}$

\begin{tabular}{|c|c|c|c|c|c|}
\hline & \multicolumn{2}{|c|}{ Men $(n=35)$} & \multicolumn{2}{|c|}{ Women $(n=27)$} & \multirow{2}{*}{$\begin{array}{l}\text { Sex difference } \\
\text { P-value }\end{array}$} \\
\hline & Mean & SD & Mean & SD & \\
\hline Age (years) & 43.0 & 7.2 & 41.4 & 7.3 & 0.3928 \\
\hline Body weight $(\mathrm{kg})^{c}$ & 92.1 & 14.1 & 74.9 & 9.7 & $<0.0001$ \\
\hline BMI $\left(\mathrm{kg} / \mathrm{m}^{2}\right)^{\mathrm{c}}$ & 29.2 & 3.2 & 28.4 & 3.2 & 0.2881 \\
\hline Waist circumference $(\mathrm{cm})^{c}$ & 102.7 & 11.0 & 94.7 & 8.1 & 0.0018 \\
\hline TAG $(\mathrm{mmol} / \mathrm{l})^{c}$ & 1.86 & 1.19 & 1.34 & 0.65 & 0.0273 \\
\hline LDL-cholesterol (mmol/l) & 3.65 & 0.72 & 3.56 & 0.51 & 0.5896 \\
\hline $\mathrm{HDL}$-cholesterol $\left(\mathrm{mmol} / \mathrm{l}^{\mathrm{c}}\right.$ & 1.12 & 0.30 & 1.33 & 0.25 & 0.0020 \\
\hline Total cholesterol/HDL-C & 5.24 & 1.03 & 4.25 & 0.77 & $<0.0001$ \\
\hline Systolic blood pressure $(\mathrm{mm} \mathrm{Hg})$ & 117.3 & 12.9 & 107.2 & 10.2 & 0.0015 \\
\hline Diastolic blood pressure $(\mathrm{mm} \mathrm{Hg})$ & 80.4 & 9.2 & 72.1 & 8.0 & 0.0005 \\
\hline Fasting glucose (mmol/l) & 5.87 & 0.37 & 5.54 & 0.44 & 0.0019 \\
\hline Mediterranean score (arbitrary units) ${ }^{d}$ & 25.1 & 6.0 & 24.5 & 4.8 & 0.6541 \\
\hline
\end{tabular}

SD standard deviation, BMI body mass index, TAG triacylglycerol, $L D L$ low-density lipoprotein, HDL high-density lipoprotein

${ }^{a}$ These characteristics were measured after the run-in period, i.e. immediately before the controlled MedDiet phase

${ }^{b}$ Sex differences were determined using the Student's $t$-test for unpaired data, except for age for which Wilcoxon-Mann-Whitney test was used

${ }^{\mathrm{C}}$ Analysis was performed on transformed values

${ }^{\mathrm{d}}$ From 0 to 44 points, a score of 44 implies a food pattern which is perfectly concordant with the traditional MedDiet 


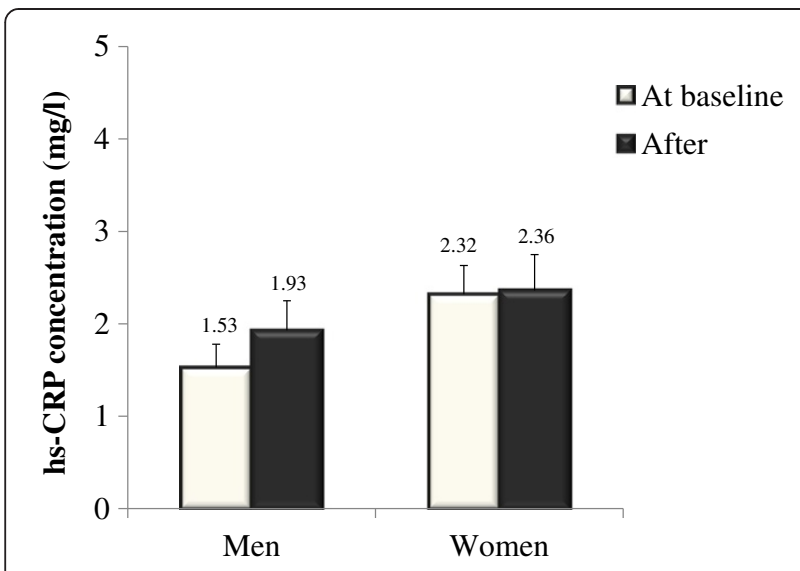

Fig. 1 hs-CRP concentrations observed in men (left, $n=35$ ) and women (right, $n=27$ ) at baseline and after the 4-week Mediterranean diet. MIXED procedures for repeated measurements followed by Tukey-Kramer tests were used. Data are means \pm SEM

elevated baseline values $(\geq 2 \mathrm{mg} / \mathrm{l}$, as defined in the Canadian guidelines for the diagnosis and treatment of dyslipidemia and prevention of CVD in the adult $[25,26])$ experienced a reduction in hs-CRP over time with the MedDiet (-26.5\%) while an increase was observed in men with lower baseline values $(<2 \mathrm{mg} / \mathrm{l},+96.6 \%$; P for groupby-time interaction among men $=0.02$; Fig. $2 \mathrm{a}$ ). This pattern of change was not observed in women ( $\mathrm{P}$ for groupby-time interaction among women $=0.11$; Fig. $2 \mathrm{~b}$ ).

Adjustments for the small but significant weight loss during the MedDiet phase $(-1.2 \mathrm{~kg}$ or $1.3 \%$ of initial body weight in men, $\mathrm{P}<0.0001$ and $-0.6 \mathrm{~kg}$ or $0.7 \%$ in women, $\mathrm{P}=0.04$; $\mathrm{P}$ for sex-by-time interaction $=0.09)$ did not influence results obtained (not shown). Changes in body weight during the controlled MedDiet were not associated with changes in hs-CRP concentrations $(r=-0.02$, $\mathrm{P}=0.89$ in men and $\mathrm{r}=-0.13, \mathrm{P}=0.52$ in women). No change was observed for waist circumference in both sexes.

\section{Discussion}

Results from this fully-controlled feeding study suggest that men and women have similar effects from the MedDiet on systemic inflammation. In fact, in this sample of individuals characterized by moderately elevated CRP concentrations, no beneficial effects from the MedDiet were observed, irrespective of the sex. However, results suggest that the variability in the anti-inflammatory effects of the MedDiet might be attributed in part to the
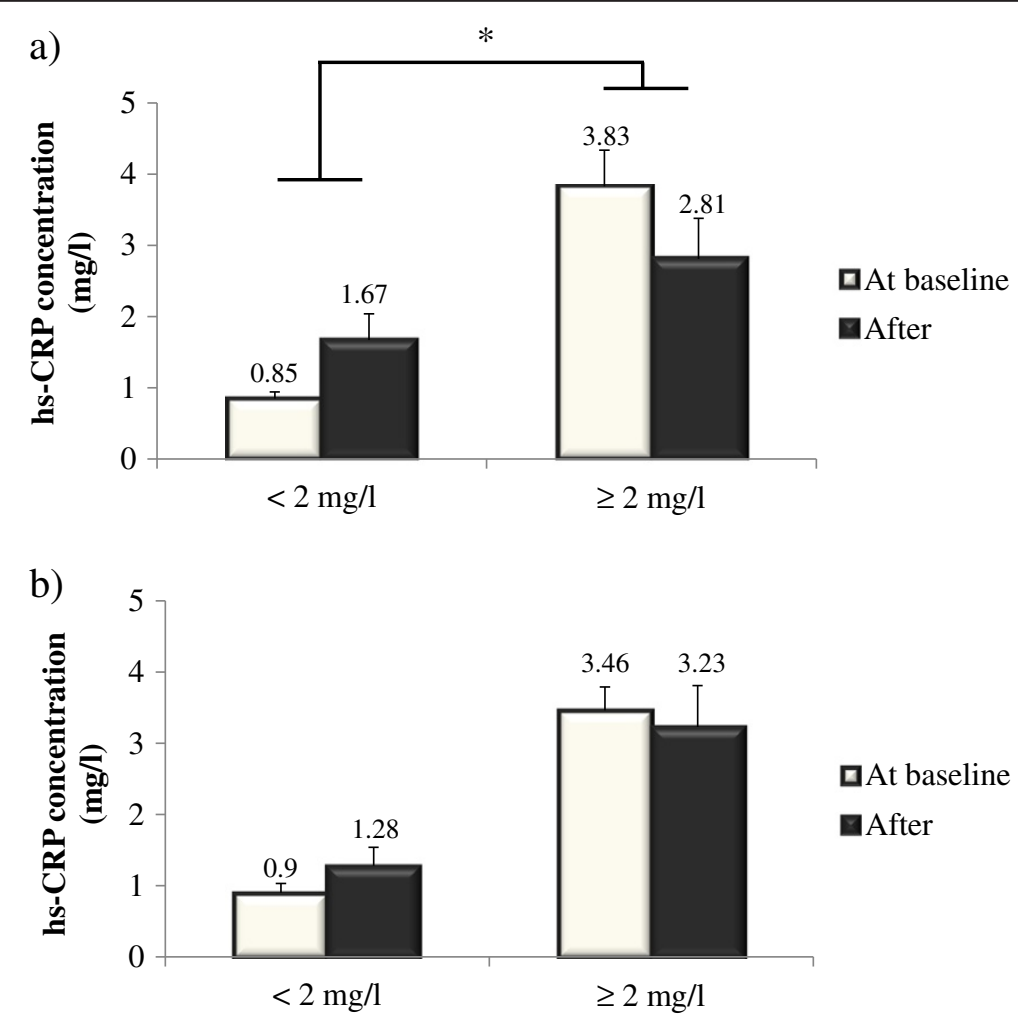

Fig. 2 hs-CRP concentrations observed in men (a) and women (b) at baseline and after the 4-week Mediterranean diet according to their hs-CRP baseline value. MIXED procedures for repeated measurements followed by Tukey-Kramer tests were used. *A group-by-time interaction was found in men $(P=0.02)$ but not in women $(P=0.11)$. Men with hs-CRP $<2 \mathrm{mg} / \mathrm{l}, \mathrm{n}=27$; men with $\mathrm{hs}-\mathrm{CRP} \geq 2 \mathrm{mg} / \mathrm{l}, \mathrm{n}=8$; women with $\mathrm{hs}-\mathrm{CRP}<2 \mathrm{mg} / \mathrm{l}$, $\mathrm{n}=12$; women with $\mathrm{hs}-\mathrm{CRP} \geq 2 \mathrm{mg} / \mathrm{l}, \mathrm{n}=15$. Data are means $\pm \mathrm{SEM}$ 
individual's overall inflammatory status but this observation seems to be more specific to men.

Despite the fact that men and women differ substantially with respect to inflammatory regulation, very limited data exist on sex differences in the impact of diet on inflammatory status. In the case of the MedDiet, an observational study has reported reduced CRP concentrations in men, but not in women, who consumed a diet more closely in accordance with the MedDiet [27] while another study observed this association irrespective of the sex [28]. For interventional trials, only the Prevención con Dieta Mediterránea (PREDIMED) study has previously documented the effects of the MedDiet on inflammatory status taking into account the sex [11]. Their study, consisting of a nutritional intervention among 772 high-risk individuals, indicates that the adherence to an energy-unrestricted MedDiet supplemented with extra-virgin olive oil reduces CRP concentrations compared with a low-fat diet, with subgroup analyses showing no difference between sexes. Results from our feeding study are therefore partly in line with those from the PREDIMED study, suggesting that the MedDiet has similar effect on inflammation in men and women.

However, our results are in disagreement with a metaanalysis of randomized controlled trials published in 2014 [5] which, as the PREDIMED study, reported a reduction of CRP concentrations with the MedDiet. However, further investigations of trials included in the meta-analysis highlight conflicting results between studies, some reporting a reduction of systemic inflammation with the MedDiet while almost half of the studies observed no significant effects. In an effort to improve our understanding of factors responsible for this divergence between studies, additional analyses from the present study suggest that the variability in the inflammatory response to the MedDiet might be attributed in part to the individual's systemic inflammatory status, i.e. those with elevated CRP concentrations having anti-inflammatory effects from the MedDiet while those with low baseline concentrations experiencing a clinically non-significant increase in response to this food pattern. However this pattern of change was more specific to men, suggesting that sex may modulate to a certain extent the impact of the MedDiet on the inflammatory status.

It is important to consider that participants included in the present study were characterized by healthy dietary habits at baseline. In fact, participants had to comply with the recommendations of the Canada's Food Guide during the four weeks preceding the controlled MedDiet phase [19]. It is therefore possible that changes in hsCRP have started during this run-in phase, limiting subsequent changes during the controlled MedDiet phase. Therefore, results from the present study should not be over-interpreted and they suggest that, compared with the Canada's Food Guide recommendations, the MedDiet has no further impact on hs-CRP concentrations.

The small body weight loss observed during the MedDiet phase may be view as a limitation. However, several studies have demonstrated that body weight loss is the best nonpharmacologic modality to reduce inflammation [29], which is in contrast with the nonsingnificant increase in hs-CRP concentrations observed in the present study. In addition, some studies have highlighted that a weight loss of at least $10 \%$ is needed to have a significant effect on the inflammatory markers in overweight and obese individuals [30]. Moreover, additional analyses showed that the adjustment for body weight changes did not influence any of the results obtained. Therefore, these observations suggest that body weight loss observed in the present study was not a major limitation.

\section{Conclusions}

Results from this feeding study suggest that the MedDiet exerts similar effects on inflammation in men and women. In addition, these results suggest that the variability in the anti-inflammatory effects of the MedDiet might be attributed in part to the individual's overall inflammatory status; however this observation seems to be more specific to men. Additional clinical studies including several inflammatory markers and a larger sample size are of importance to further document the impact of sex on the inflammatory response to the MedDiet.

\section{Abbreviations}

CRP: C-reactive protein; MedDiet: Mediterranean diet; hs-CRP: High-sensitivity C-reactive protein; LDL-C: Low-density lipoprotein cholesterol; HDL-C: Highdensity lipoprotein cholesterol; TAG: Triacylglycerol; FFQ: Food frequency questionnaire; BMI: Body mass index; SD: Standard deviation.

\section{Competing interests}

The authors declare that they have no competing interest.

\section{Authors' contributions}

SL designed the research; $A B$ and LC conducted the research; SD supervised the medical condition of participants; $A B$ analyzed the data and wrote the first draft of this paper; all authors participated to the interpretation of data and revised critically and approved the final version of the paper.

\section{Acknowledgements}

The authors would like to thank Johanne Marin for her contribution in the laboratory. This research was supported by the Canadian Institutes of Health Research (grant number: MOP 84568) and the Heart and Stroke Foundation of Quebec (grant number: 2007-180). AB is a recipient of a studentship from Canadian Institutes of Health Research (CIHR). BL is Chair of Nutrition at Laval University.

\section{Author details}

${ }^{1}$ Institute of Nutrition and Functional Foods (INAF), 2440 Hochelaga Boulevard, Laval University, Québec, Qc G1V 0A6, Canada. School of Nutrition, Pavillon Paul-Comtois, 2425 rue de l'Agriculture, Laval University, Québec, Qc G1V 0A6, Canada. ${ }^{3}$ Department of Obstetrics and Gynaecology, Pavillon Ferdinand-Vandry, 1050 Medicine Avenue, Laval University, Québec, Qc G1V 0A6, Canada.

Received: 26 January 2015 Accepted: 1 May 2015

Published online: 12 May 2015 


\section{References}

1. Libby P, Okamoto Y, Rocha VZ, Folco E. Inflammation in atherosclerosis: transition from theory to practice. Circ J. 2010;74:213-20. http://doi.org/ 10.1253/circj.CJ-09-0706.

2. Buckley DI, Fu R, Freeman M, Rogers K, Helfand M. C-reactive protein as a risk factor for coronary heart disease: a systematic review and meta-analyses for the U.S. Preventive Services Task Force. Ann Intern Med. 2009;151:483-95. doi:10.7326/0003-4819-151-7-200910060-00009.

3. Emerging Risk Factors Collaboration, Kaptoge S, Di Angelantonio E, Lowe G, Pepys MB, Thompson SG, et al. C-reactive protein concentration and risk of coronary heart disease, stroke, and mortality: an individual participant metaanalysis. Lancet. 2010;375:132-40. doi:10.1016/S0140-6736(09)61717-7.

4. Lee CC, Adler Al, Sandhu MS, Sharp SJ, Forouhi NG, Erqou S, et al. Association of $C$-reactive protein with type 2 diabetes: prospective analysis and metaanalysis. Diabetologia. 2009;52:1040-7. doi:10.1007/s00125-009-1338-3.

5. Schwingshackl L, Hoffmann G. Mediterranean dietary pattern, inflammation and endothelial function: a systematic review and meta-analysis of intervention trials. Nutr Metab Cardiovasc Dis. 2014;24:929-39. doi:10.1016/j.numecd.2014. 03.003.

6. Willett WC, Sacks F, Trichopoulou A, Drescher G, Ferro-Luzzi A, Helsing E, et al. Mediterranean diet pyramid: a cultural model for healthy eating. Am J Clin Nutr. 1995;61:1402S-6S.

7. Richard C, Couture P, Desroches S, Lamarche B. Effect of the Mediterranean diet with and without weight loss on markers of inflammation in men with metabolic syndrome. Obesity (Silver Spring). 2013;21:51-7. doi:10.1002/ oby.20239.

8. Athyros VG, Kakafika Al, Papageorgiou AA, Tziomalos K, Peletidou A, Vosikis C, et al. Effect of a plant stanol ester-containing spread, placebo spread, or Mediterranean diet on estimated cardiovascular risk and lipid, inflammatory and haemostatic factors. Nutr Metab Cardiovasc Dis. 2011;21:213-21. doi:10.1016/j.numecd.2009.08.014

9. Esposito K, Pontillo A, Di Palo C, Giugliano G, Masella M, Marfella R, et al. Effect of weight loss and lifestyle changes on vascular inflammatory markers in obese women: a randomized trial. JAMA. 2003;289:1799-804. doi:10.1001/ jama.289.14.1799.

10. Esposito K, Marfella R, Ciotola M, Di Palo C, Giugliano F, Giugliano G, et al. Effect of a mediterranean-style diet on endothelial dysfunction and markers of vascular inflammation in the metabolic syndrome: a randomized trial. JAMA. 2004;292:1440-6.

11. Estruch R, Martinez-Gonzalez MA, Corella D, Salas-Salvado J, Ruiz-Gutierrez V, Covas Ml, et al. Effects of a Mediterranean-style diet on cardiovascular risk factors: a randomized trial. Ann Intern Med. 2006;145:1-11. doi:10.7326/ 0003-4819-145-1-200607040-00004

12. Djuric Z, Ren J, Blythe J, VanLoon G, Sen A. A Mediterranean dietary intervention in healthy American women changes plasma carotenoids and fatty acids in distinct clusters. Nutr Res. 2009;29:156-63. doi:10.1016/ j.nutres.2009.03.001.

13. Itsiopoulos C, Brazionis L, Kaimakamis M, Cameron M, Best JD, O'Dea K, et al. Can the Mediterranean diet lower HbA1c in type 2 diabetes? Results from a randomized cross-over study. Nutr Metab Cardiovasc Dis. 2011;21:740-7. doi:10.1016/..numecd.2010.03.005

14. Michalsen A, Lehmann N, Pithan C, Knoblauch NT, Moebus S, Kannenberg F, et al. Mediterranean diet has no effect on markers of inflammation and metabolic risk factors in patients with coronary artery disease. Eur J Clin Nutr. 2006;60:478-85. doi:10.1038/sj.ejcn.1602340.

15. Sexton P, Black $P$, Metcalf $P$, Wall CR, Ley $S, W u$, et al. Influence of mediterranean diet on asthma symptoms, lung function, and systemic inflammation: a randomized controlled trial. J Asthma. 2013;50:75-81. doi:10.3109/02770903.2012.740120.

16. Yang Y, Kozloski M. Sex differences in age trajectories of physiological dysregulation: inflammation, metabolic syndrome, and allostatic load. J Gerontol A Biol Sci. 2011;66:493-500. doi:10.1093/gerona/glr003.

17. Chakrabarti S, Lekontseva O, Davidge ST. Estrogen is a modulator of vascular inflammation. lubmb Life. 2008;60:376-82.

18. Carruba G, Granata OM, Pala V, Campisi I, Agostara B, Cusimano R, et al. A traditional Mediterranean diet decreases endogenous estrogens in healthy postmenopausal women. Nutr Cancer. 2006;56:253-9. doi:10.1207/ s15327914nc5602_18.

19. Bedard A, Riverin M, Dodin S, Corneau L, Lemieux S. Sex differences in the impact of the Mediterranean diet on cardiovascular risk profile. $\mathrm{Br} J$ Nutr. 2012;108:1428-34. doi:10.1017/S0007114511006969.
20. Minister of Health Canada. Eating Well with Canada's Food Guide. 2007. http://www.hc-sc.gc.ca/fn-an/alt_formats/hpfb-dgpsa/pdf/food-guidealiment/view_eatwell_vue_bienmang-eng.pdf. Accessed 14 Jan 2015.

21. Bedard A, Dodin S, Corneau L, Lemieux S. The impact of abdominal obesity status on cardiovascular response to the mediterranean diet. J Obes. 2012;2012:969124. doi:10.1155/2012/969124.

22. Goulet J, Nadeau G, Lapointe A, Lamarche B, Lemieux S. Validity and reproducibility of an interviewer-administered food frequency questionnaire for healthy French-Canadian men and women. Nutr J. 2004;3:13.

23. Ridker PM. Clinical application of C-reactive protein for cardiovascular disease detection and prevention. Circulation. 2003;107:363-9. doi:10.1161/ 01.CIR.0000053730.47739.3C.

24. Goulet J, Lamarche B, Nadeau G, Lemieux S. Effect of a nutritional intervention promoting the Mediterranean food pattern on plasma lipids, lipoproteins and body weight in healthy French-Canadian women. Atherosclerosis. 2003;170:115-24. http://dx.doi.org/10.1016/S0021-9150(03) 00243-0.

25. Anderson TJ, Gregoire J, Hegele RA, Couture P, Mancini GB, McPherson R, et al. 2012 update of the Canadian Cardiovascular Society guidelines for the diagnosis and treatment of dyslipidemia for the prevention of cardiovascular disease in the adult. Can J Cardiol. 2013;29:151-67. doi:10.1016/j.cjca.2012.11.032.

26. Genest J, McPherson R, Frohlich J, Anderson T, Campbell N, Carpentier A, et al. 2009 Canadian Cardiovascular Society/Canadian guidelines for the diagnosis and treatment of dyslipidemia and prevention of cardiovascular disease in the adult - 2009 recommendations. Can J Cardiol. 2009;25:567-79.

27. Carter SJ, Roberts MB, Salter J, Eaton CB. Relationship between Mediterranean Diet Score and atherothrombotic risk: findings from the Third National Health and Nutrition Examination Survey (NHANES III), 19881994. Atherosclerosis. 2010;210:630-6. doi:10.1016/j.atherosclerosis. 2009.12.035.

28. Panagiotakos DB, Dimakopoulou K, Katsouyanni K, Bellander T, Grau M, Koenig W, et al. Mediterranean diet and inflammatory response in myocardial infarction survivors. Int J Epidemiol. 2009;38:856-66. doi:10.1093/ ije/dyp142.

29. Devaraj S, Kasim-Karakas S, Jialal I. The effect of weight loss and dietary fatty acids on inflammation. Curr Atheroscler Rep. 2006;8:477-86.

30. Forsythe LKS, Wallace JM, Livingstone MB. Obesity and inflammation: the effects of weight loss. Nutr Res Rev. 2008;21:117-33. doi:10.1017/S09544224 08138732.

\section{Submit your next manuscript to BioMed Central and take full advantage of:}

- Convenient online submission

- Thorough peer review

- No space constraints or color figure charges

- Immediate publication on acceptance

- Inclusion in PubMed, CAS, Scopus and Google Scholar

- Research which is freely available for redistribution 